\title{
An Upward Fire Spread and Growth Simulation
}

\author{
M. M. DELICHATSIOS, M. K. MATHEWS and M. A. DELICHATSIOS
}

Factory Mutual Research Corporation

Norwood, Massachusetts 02062, USA

ABSTRACT

A computer simulation for upward fire spread has been developed. The simulation of the fire growth and spread consists of four major components (modules): 1) preheating of the unburned fuel, 2) upward fire spread, i.e. determination of the location of the pyrolysis front, 3) pyrolysis of the material, and 4) combustion of the pyrolyzing gases. For the heat-up and pyrolysis modules of the code, integral models have been used which accurately predict (within 1\% to $2 \%$ ) transient heat-up and transient pyrolysis when compared with exact analytical solutions. The pyrolysis front location, $z_{p}$, is calculated to order $(\Delta z)^{2}$ by taking an intercept of a straight Ine, connecting the temperatures (real and/or virtual) of the nodes containing $Z_{p}$, with the pyrolysis temperature $T_{p}$. The combustion module of the code calculates the heat flux distribution on the wall from the combustion of the pyrolyzing gases by providing expressions for the flame height, $Z_{f}$, the convective, $\mathrm{q}_{\mathrm{c}}^{\prime \prime}$, and radiative heat fluxes, $\dot{q}_{r}^{\prime \prime}$, based on experimental data from the literature. The components as well as the whole algorithm of the Upward Fire Spread and Growth (UFSG) code have been compared against exact analytical solutions including transient heat-up, transient pyrolysis and flame spread. As an example, it is demonstrated that transient pyrolysis even for non-charring materials significantly affects upward fire spread rates. This result explains recent experimental data on laminar upward flame spread. In addition, a comparison of numerical predictions with turbulent upward flame spread data is made, and the results are very satisfactory.

KEYWORDS: Fire Simulation, Flame Spread, Pyrolysis

\section{NOMENCLATURE}

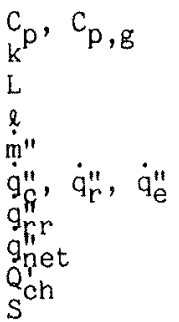

specific heat of wall material and of combustion gases thermal conductivity

latent heat of vaporization

thickness of wall

mass pyrolysis rate per unit area

convective, radiative, extemal heat flux to the wall

reradiation wall losses

net heat flux: $\dot{q}_{e}^{\prime \prime}+\dot{q}_{c}^{\prime \prime}+\dot{q}_{r}^{\prime \prime}+\dot{q}_{r r}^{\prime \prime}$

heat release rate of pyrolyzing gases per unit wall length

mass stoichiometric air to fuel ratio 


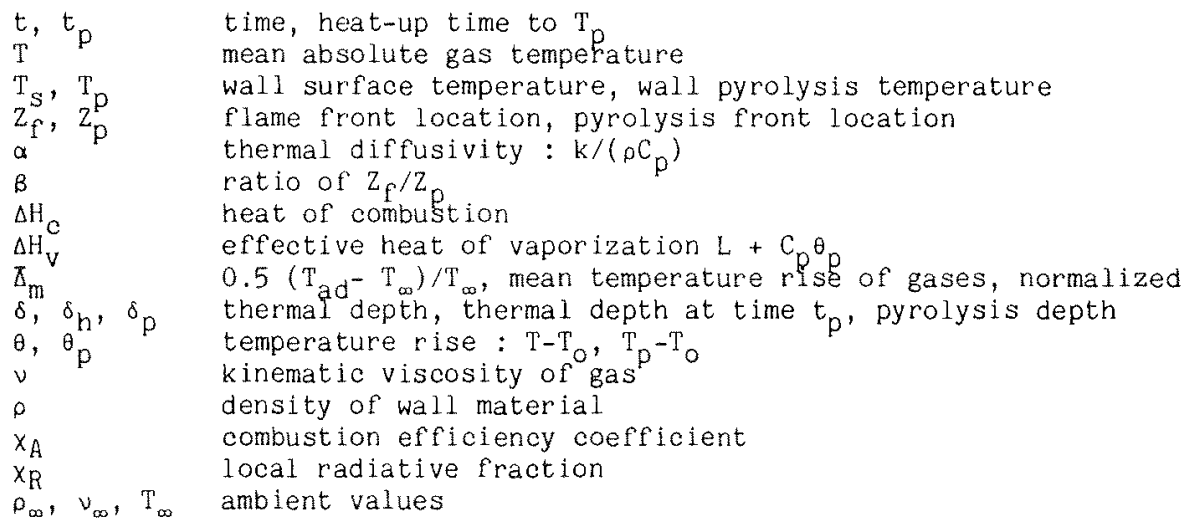

\section{INTRODUCTION}

This paper describes modeling of fire growth for fire situations. The philosophy for the development of the present upward fire spread and growth (UFSG) simulation has been to use the best models $[1,2,3,4,5]$ to describe the physics with the restriction that the input material properties required for these models should be measurable in existing flammability apparatuses.

For any fire situation including burning of a vertical wall surface, there are four components to be included in a practical model of fire growth: 1) preheating of the unburned fuel, 2) pyrolysis of the material, 3) burning of the pyrolyzing gases, and 4) fire spread - upward, downward or lateral. Downward or lateral flame spread reach steady conditions and are slower than upward flame spread. In contrast, upward flame spread is much faster and depends also on the scale of the fire for two reasons: 1) the flame heights increase with the scale, 2) flame radiation increases with scale. One may conclude that upward flame spread is a critical component in a growing fire and in addition it might be used to characterize in a rational way the fire hazard of a material, including scale effects.

This paper includes the physical aspects and general structure of the program, the submodels, comparison tests for the submodels against exact analytical solutions, and a comparison for upward flame spread on a noncharring wall, such as PMMA. The present version of the UFSG code has not addressed completely (i.e. with full validation) the following situations which will be included in improved versions of the program; 1) Charring materials, 2) In-depth radiation absorption, 3) Wall surface cooling.

\section{PHYSICAL ASPECTS AND STRUCTURE OF THE PROGRAM}

Figure 1 depicts the 2-D vertical wall fire situation modeled here. The wall is modeled as consisting of vertical sections (zones) exposed to heating from the flame and/or other external heat fluxes. The components of the fire consist of: 1) gaseous burning, 2) heat-up of the wall, 3) pyrolysis, and 4) pyrolysis front spread. The general structure of the UFSG program and the interrelation between the different submodules is shown in Eigure 2. At every time step the program performs first a "predictor" calculation and then a "corrector" calculation to correct for the interdependence between the heat flux from the flames and the amount of pyrolyzing gases. 


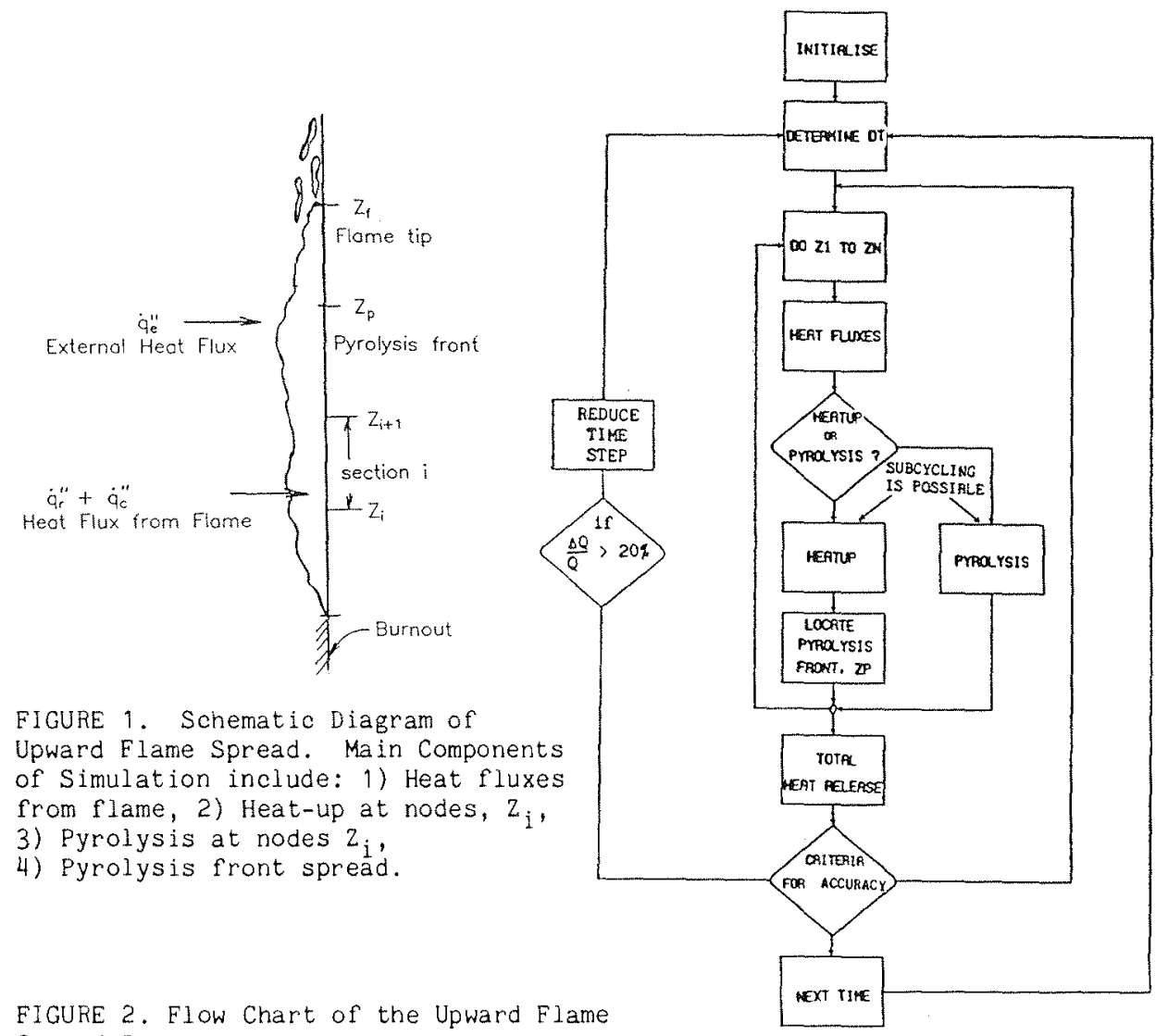

Spread Program

In the "predictor" calculation the wall nodes where the surface temperature has not reached the pyrolysis temperature, $T_{p}$, are directed to the "heat-up" module, whereas the wall nodes that have reached or exceeded $T_{\text {}}$ are directed to the "pyrolysis" module. At this point the algorithm for locating the pyrolysis front, $z_{n}$, is actuated to produce an estimated value for at the new time. The "pyrolysis" module calculates a mass pyrolysis rate at the new time assuming the old net heat flux during the whole time-step. It also calculates the total heat release rate from the pyrolyzing gases. This information enters the "total heat release" module where the convective and radiative components of heat flux are calculated at the new time.

With these new estimates the cycle is repeated as a "corrector step", using a corrected net heat flux during the current time-step equal to the average of the old and the new heat fluxes, thus making the algorithm second-order accurate in time. Prior to performing the corrector step though, criteria for accuracy are applied on the radiative heat flux and the mass pyrolysis rate at the new time level. If the estimated radiative heat flux at any node, $i$, or the total pyrolysis rate at the new time exceed their values at the beginning of the time-step by more than a specified value $(e . g .20 \%)$, the time-step is reduced and the procedure is repeated. 
a) INTEGRAL MODEL. FOR HEAT-UP

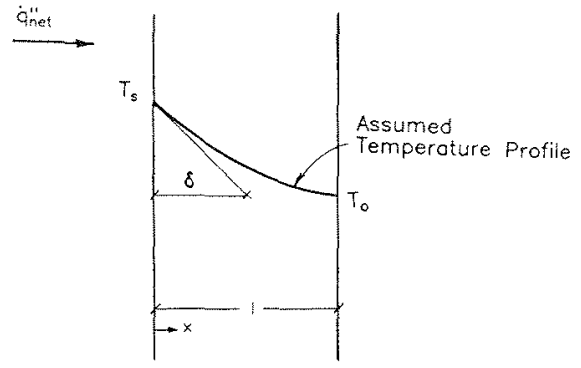

b) INTEGRAL. MODEL FOR NON-CHARRING PYROLYSIS

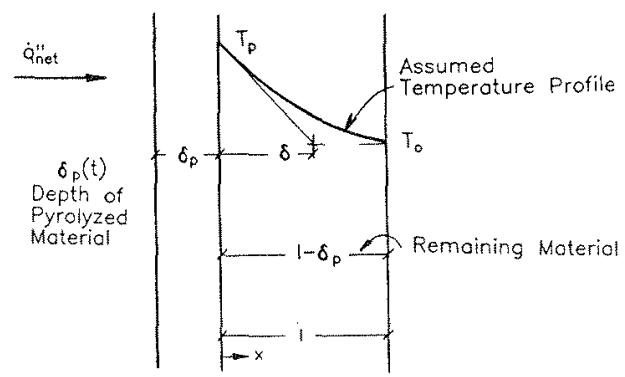

FIGURE 3. Integral Model for Heat-up and Non-Charring Pyrolysis

a) Heat-up: Temperature Profile: $\theta=T-T_{0}=\theta_{S}(t) e^{-x / \delta}$ where $\theta_{S}=T_{S}-T_{0}$

b) Pyrolysis: Temperature Profile: $\theta=T-T_{0}=\theta_{p} e^{-\left(x-\delta_{p}\right) / \delta}$ where $\theta_{p}=T_{p}-T_{0}$

\section{PHYSICAL MODELS FOR HEAT-UP AND PYROLYSIS}

The integral models for heat-up and pyrolysis are developed to reduce the computational effort of solving the partial differential heat conduction equations. The models, shown on Fig. 3a and Fig. 3b, employ an exponential temperature profile across the wall, of thickness $\ell$, and solve the first two moments of the 1-D heat conduction equation. The resulting equations, assuming the wall properties $k, \rho, C_{p}$ constant, are [2]:

\section{For heat-up:}

$\frac{\mathrm{d}}{\mathrm{dt}}\left[\theta_{\mathrm{s}} \delta\left(1-\mathrm{e}^{-\ell / \delta}\right)\right]=\frac{\dot{\mathrm{q}}_{\text {net }}^{\prime \prime}}{\rho \mathrm{C}_{\mathrm{p}}}$

$\frac{d}{d t}\left[\theta_{s}^{2} \delta\left(1-e^{-2 \ell / \delta}\right)\right]=4 \theta_{s} \frac{\dot{q}_{n e t}^{\prime \prime}}{\rho C_{p}}-4 a \frac{\theta_{s}^{2}}{2 \delta}\left(1-e^{-2 \ell / \delta}\right)$

with initial conditions

$$
\theta_{S}(t=0)=0, \quad \delta(t=0)=0
$$

For pyrolysis:

$\frac{\mathrm{d}}{\mathrm{dt}}\left[\theta_{\mathrm{p}} \delta\left(1-\mathrm{e}^{-\left(\ell-\delta_{\mathrm{p}}\right) / \delta}\right)\right]+\dot{\delta}_{\mathrm{p}} \theta_{\mathrm{p}}\left[1+\frac{\mathrm{L}}{\mathrm{C}_{\mathrm{p}} \theta_{\mathrm{p}}}\right]=\frac{\dot{q}_{\text {net }}^{\prime \prime}}{\rho \mathrm{C}_{\mathrm{p}}}$

$\frac{d}{d t}\left[\theta_{p}^{2} \delta\left(1-e^{-2\left(\ell-\delta_{p}\right) / \delta}\right)\right]+2 \dot{\delta} \theta_{p}^{2}\left[1+\frac{2 L}{C_{p} \theta_{p}}\right]=4 \theta_{p} \frac{\dot{q}_{n e t}^{\prime \prime}}{\rho C_{p}}-4 a \frac{\theta_{p}^{2}}{2 \delta}\left(1-e^{-2(\ell-\delta p) / \delta}\right)$

with initial conditions: $\quad \delta\left(t=t_{p}\right)=\delta_{\text {heat-up }}, \quad \delta_{p}\left(t=t_{p}\right)=0$

The pyrolysis rate is: $\dot{m}^{\prime \prime}=\rho\left(d \delta_{p} / d t\right)$

Equations (1) and (2) constitute a system of ordinary differential equations for $\theta_{s}$ (surface temperature rise) and $\delta$ (thermal length) as a function of time while the pyrolysis equations (4) and (5) are solved for $\delta$ and $\delta$ (the depth of the material pyrolyzed). Standard ODE solvers can be used fof the solution of these equations. The heat-up process is terminated when the surface temperature reaches the pyrolysis temperature, $\mathrm{T}_{\mathrm{p}}$ which remains constant during pyrolysis. 


\section{DETERMINATION OE THE PYROLYSIS FRONT LOCATION, $z_{p}$}

Once the computation of heat up is complete for the $i-t h$ node, nodes i and $i-1$ can be examined to determine whether the pyrolysis front is present between the nodes. If both temperatures are below $\mathrm{T}$ then the entire section is still undergoing heat $u p$. If both temperatures are above $\mathrm{T}$, then the entire section is undergoing pyrolysis and the pyrolysis front must exist (if it exists at all) in some other section. If one node is above and the other node below $\mathrm{T}$ then the front must be between the nodes and we can estimate its location by taking an intercept of a straight line, connecting the temperatures (real and/or virtual) of the two nodes, with $\mathrm{T}_{\mathrm{p}}$. Virtual temperature is the temperature $\left(\mathrm{T}_{\mathrm{v}}>\mathrm{T}_{\mathrm{p}}\right)$ that the node would have reached, while being heated, if it had not started to pyrolyze.

\section{COMBUSTION MODEL AND ELAME HEAT FLUXES}

An essential part of the upward flame spread simulation is the net heat flux from the flames of the wall fire to the wall. The net heat flux to the wall consists of a) the convective heat flux from the flames, b) the radiative heat flux from the flames, and $\mathrm{c})$ the surface reradiation losses. The magnitude and distribution of these fluxes depend on the gaseous combustion of the pyrolyzing gases which determines the vertical extent of combustion (flame height, $Z_{f}$ ) and the heat release rate per unit length $\left(\dot{Q}_{\mathrm{ch}}^{\prime}\right)$.

An integral combustion model [1] for wall fires allows the calculation of convective heat fluxes, the heat release rate, and the flame height $[1,6]$. The radiative heat fluxes cannot yet be determined from a combustion model, but they are obtained from recent experimental correlations [7]. In the current version of the upward flame spread simulation, simple expressions are suggested for the flame heights and heat fluxes. Table 1 ists the suggested combustion model options. For each option, a model is suggested [2]. The effect of the various options on fire spread will be tested in the near future in a comprehensive sensitivity analysis. The first column of Table 1 lists the options for the flame height. Three options are suggested, based on experimental data $[1,8,10,7 \mathrm{a}]$. The next three columns 1 ist the options for the flame heat fluxes. In all cases the flame heat fluxes are zero beyond the flame height.

TABLE 1. Combustion Model Options for Upward Turbulent Elame Spread (Columns are Independent)

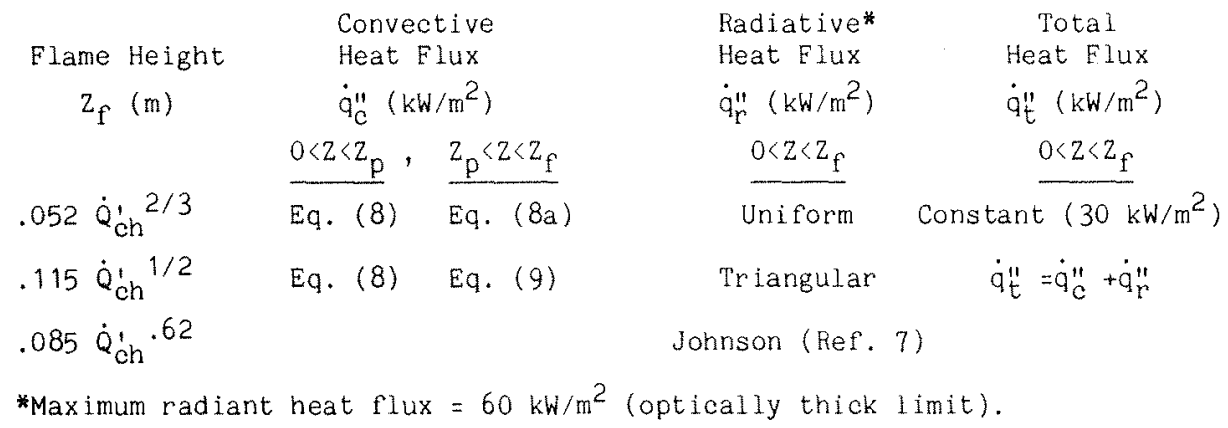


Convective Heat Flux: For the convective heat flux, eq. ( 8 ) below gives the local convective heat flux at node, $i$, up to the pyrolysis height, $z_{p}$ and is based on the convective mass transfer number. [2] For PMMA, using typical values, for $\Delta H_{C}=25300 \mathrm{~kJ} / \mathrm{kg}, x_{A}=1.0, x_{R}=0.3, \quad \rho_{\infty} \equiv 1.2 \mathrm{~kg} / \mathrm{m}^{3}$, $v_{\infty}=1.5 \times 10^{-5} \mathrm{~m}^{2} / \mathrm{s}, T_{\mathrm{T}}, i=T_{p}=640^{\circ} \mathrm{K}, \mathrm{T}_{\infty}=298 \mathrm{~K}^{\circ} \mathrm{K}, \mathrm{g}=9.81 \mathrm{~m} / \mathrm{s}^{2}, \mathrm{~S}=8.5$, $\nabla_{\mathrm{m}}^{\infty}=3.0$ we obtain $\dot{q}_{\mathrm{c}, i}^{\prime \prime}=14^{\mathrm{p}} \mathrm{kW} / \mathrm{m}^{2}$. This value is consistent with experimental measurements by Markstein [7].

$$
\dot{q}_{c, 1}^{\prime \prime}=\frac{\Delta H_{c}\left(x_{A}-x_{R}\right) /\left(S x_{A}\right)-c_{p, g}\left(T_{s, i}-T_{\infty}\right)}{\exp \left[\dot{m}_{i}^{\prime \prime} /\left(.088 \rho_{c o}\left(v_{\infty} g \bar{b}_{m}\right)^{1 / 3}\right)\right]-1} \dot{m}_{i}^{\prime \prime} \quad, 0<z<z_{p}
$$

Beyond the pyrolysis height two expressions are suggested: eq. (8b) is the limit of eq. (8a) for $\dot{m}_{i}^{\prime \prime} \rightarrow 0$ while eq. (9) is a correlation of experimental data. [11] The power $4 / 3$ in eq. (9) is related to the power dependence of natural convective heat fluxes on temperature (i.e. $\dot{q}_{c}^{\prime \prime} \sim \Delta T^{4 / 3}$ ).

$$
\begin{aligned}
& \frac{z_{p}<z<z_{f}}{\dot{q}_{c, i}^{\prime \prime}=.088} \rho_{\infty}\left(v_{\infty} g \bar{\Delta}_{m}\right)^{1 / 3}\left[\Delta H_{c}\left(x_{A}-x_{R}\right) /\left(S x_{A}\right)-c_{p, g}\left(T_{s, i}-T_{\infty}\right)\right] \\
& \dot{q}_{c}^{\prime \prime}=25\left(x_{A}-x_{R}\right)^{4 / 3} \quad(\text { Ref. } 2,14) \quad\left(\dot{q}_{c}^{\prime \prime} \text { in } k W / m^{2}\right)
\end{aligned}
$$

Equations ( $8 \mathrm{~b}$ ) and (9) are not basically different as one can convince himself by noticing that the parenthesis in eq. (8b) represents the flame adiabatic temperature rise, as well as the parameter $\Delta_{\mathrm{m}}$ does (see Nomenclature), i.e., both equations imply that $\dot{q}_{\mathrm{c}}^{\prime \prime} \sim \Delta \mathrm{T}^{4 / 3}$. Equation $(8 \mathrm{~b})$ is general while eq. (9) is based on the observation that the adiabatic flame temperature is nearly the same for most of the practical fuels.

Flame Radiative Flux. To calculate the radiant flux from the flames as a function of height, we first calculate the instantaneous total heat release and then assume a simple radiant flux profile versus height, based on observations and/or measurements from typical flames. The instantaneous total radiant heat release to the wall is:

$\frac{1}{2} x_{R} \dot{Q}_{c h}^{\prime}=\frac{1}{2} x_{R} \sum\left(\dot{m}_{i}^{\prime \prime} \Delta Z_{i}\right) \cdot \Delta H_{c}$

where $\Delta z_{i}$ is the height of the $i^{\text {th }}$ segment of the pyrolyzing wall, and the factor $\frac{1}{2}$ shows that half the radiation from the flames is directed to the wall. Three options are proposed in Tabie 1 for the vertical distribution of radiant heat flux: uniform profile, triangular profile [7b] with a maximum at a height $0.4 \mathrm{z}_{\mathrm{f}}$ and a bell-shape Johnson distribution profile [7]. In all cases a maximum radiant heat flux of $60 \mathrm{~kW} / \mathrm{m}^{2}$ is assumed in the model (optically thick limit).

Total Heat Flux. Based on various experiments $[4,5]$ the following expression for the total flame heat flux is suggested (see Table 1):

$\dot{q}_{t}^{\prime \prime}=$ fixed $=30 \mathrm{~kW} / \mathrm{m}^{2}$ for short walls $\left(z_{\mathrm{f}} \leq 1.5 \mathrm{~m}\right)$

$\dot{q}_{t}^{\prime \prime}=\dot{q}_{c}^{\prime \prime}+\dot{q}_{r}^{\prime \prime}$

for long walls $\left(z_{f}>1.5 \mathrm{~m}\right)$

Beyond the height, $z_{f}$, the present model assumes $\dot{q}_{t}^{\prime \prime}=0$. Future versions will incorporate a smooth decay in accordance with experimental data [4]. 
In this section we test the accuracy of the integral model approximation for the heat up and pyrolysis models against exact analytical solutions. As examples for the heat-up models we choose: a) constant applied heat flux and b) combinations of steps of constant heat flux. The examples with steps in the external heat flux are designed to test the validity of the physical model, as well as the numerical schemes employed, to their Iimits. A comparison with a constant applied heat flux for a thermally thick solid $(\ell>>\delta)$ can be done directly by neglecting the exponentials in eqs. (1) and (2) and solving them exactly (see Ref. 2). The solution, when compared to the exact heat conduction equation, shows that the integral model equations predict very accurately (error $1 \%$ ) the heat-up of the wall.

Figure 4 a shows a comparison with the exact analytical solution when steps of external heat flux are applied. Note that the accuracy of the integral model solution (solid line) compared with the analytical solution (dotted line) is remarkably good. Note that the accuracy of the predicted solution after the second step at a normalized time $E=t / t=1.0$ is crude during a few time steps but is remarkably good thereafter. An interesting observation of Figure 4 a concerns the thermal depth. The normalized thermal depth, $\tilde{\delta}=\delta / \delta$, increases to a value equal to 1.0 at $E=1.0$ and then drops suddenly when the new step in heat flux occurs at $E=1.0$. This is the way that the integral model accommodates the new thermal layer that starts to develop near the surface when a sudden large neat flux is applied. More tests for several external heat fluxes can be found in [2]. The integral model approximation of the pyrolysis submodel is being tested (see Ref. 2) against two "exact" analytical solutions for q" is shown that the error in predicting the mass pyrolysis rate is less than 2\%. Figure $4 \mathrm{~b}$ shows a comparison of the integral model prediction with an exact analytical solution in the limit when $\left(\mathrm{L} / \mathrm{C}_{\mathrm{p}} \hat{\theta}_{\mathrm{p}}\right)+\infty$. As can be seen from this figure, the accuracy of the integral model approximation is remarkably good.
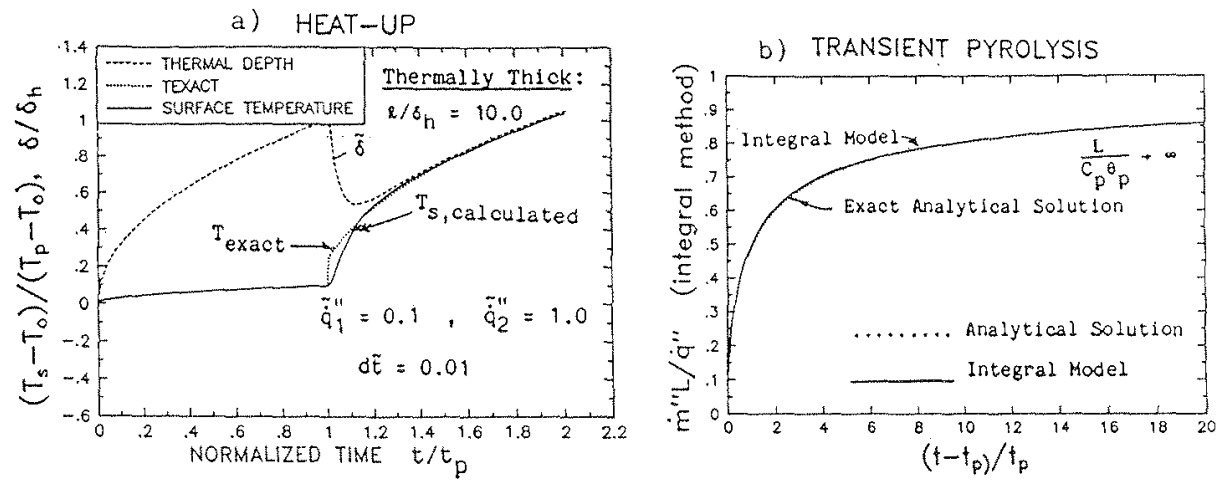

FIGURE 4 Comparison Test for Heat-up and Pyrolysis, Thermally thick solid:

a) Heat-up: Wall surface temperature comparison between integral model prediction and analytical solution for a sudden increase in heat flux: Normalizing quantities: $\dot{q}^{\prime \prime}, \theta_{p}, t_{p}=\frac{\pi \alpha}{4}, \frac{\pi \alpha}{4}\left(\rho c_{p} \theta_{p} / \dot{q}^{\prime \prime}\right)^{2}, \quad s_{h}=\left(\frac{4 a}{5 t_{p}}\right)^{1 / 2}$.

b) Transient Pyrolysis, $\dot{q}^{\prime \prime}=$ const: Comparison with an Exact Analytical Solution for $L / C_{p} \theta_{p}+\infty$ 


\section{COMPARISON TESTS FOR OVERALL ALGORITHM}

Comparison tests for the overall performance of the code are performed against an exact analytical solution for a thermally thick, non-charring wall which is calculated for a net heat flux to the wall, qnet $\sim z^{-1 / 4}$. This solution corresponds to a simulation of laminar upward flame spread in which flame radiation and reradiation losses are negligible.

When the externally applied heat flux varies as $\dot{q}_{n e t}^{\prime \prime} \sim 2^{-1 / 4}$ with height, one can obtain a similarity solution for which the ratio of the flame height to the pyrolysis length is constant, $1 . e . Z_{f} / Z_{n}=B$. We can then calculate analytically the fire spread rate [2] as a function of $B$ :

$$
z_{p}^{1 / 2}=\frac{4}{\pi k \rho C_{p} \cdot \theta_{p}^{2}}\left(1-\frac{1}{\sqrt{B}}\right) A^{2} t
$$

It can be shown $[2,14]$ that the parameter $B$ for transient pyrolysis is significantly less than its value for quasi-steady pyrolysis. Therefore, an estimate of the pyrolysis front spread rate assuming quasi-steady pyrolysis, overestimates substantially the spread rate. This result is supported by experimental data [12] where theoretical predictions of spread rates based on quasi-steady pyrolysis overestimate measured spread rates.

Figure 5 a shows plots of the ratio $\beta=z_{f} / z_{p}$ and of $z_{p}^{1 / 2}$ versus time for fire spread over a vertical wall of flammable height equal to $0.2 \mathrm{~m}$. By keeping the flammable height at a limited value, we follow the transient pyrolysis, initially, as well as the transition to quasi-steady pyrolysis at later times. The figure shows that, after a very short period, the ratio $\mathrm{Z}_{\mathrm{f}} / \mathrm{Z}_{\mathrm{p}}$ reaches, indeed, a constant value, $B$, during transient pyrolysis, where $B=2.15$ in our example. Figure $5 a$ also shows that $2_{p}^{1 / 2}$ grows linearly with time during transient pyrolysis, as expected from eq. (12). Fig. 5b shows results for the heat release rate. The excellent agreement verifies the soundness of the present numerical code.

\section{TRANSIENT PYROLYSIS - LAMINAR UPWARD FLAME SPREAD}
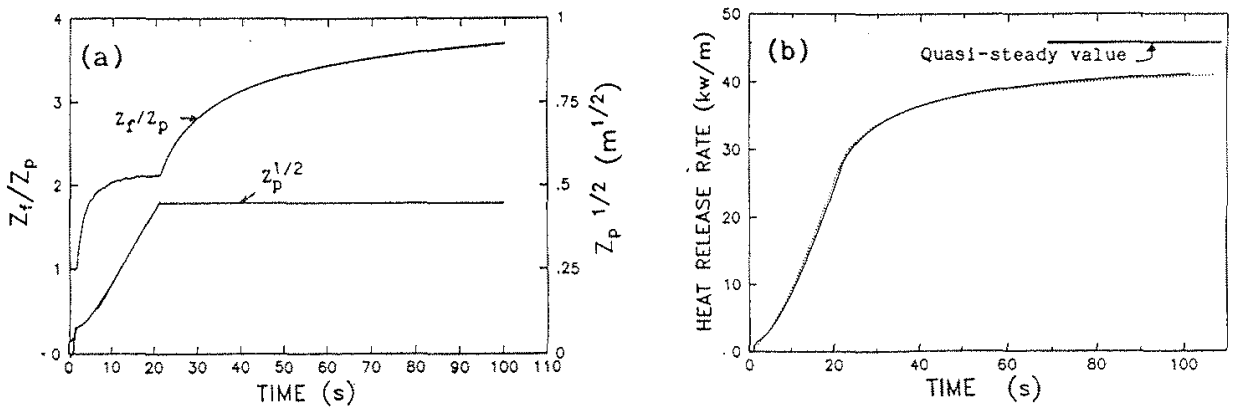

FIGURE 5 Comparison Tests for Overail Algorithm for $\dot{q}_{\text {net }}^{\prime \prime}=8.42 z^{-1 / 4}$ Note that the material is not PMMA.

$C_{p}=1.5 \mathrm{~kJ} / \mathrm{kg},{ }^{\circ} \mathrm{K},{ }_{\mathrm{p}}{ }_{\mathrm{p}}=\mathrm{T}_{\mathrm{p}}{ }^{-} \mathrm{T}_{\mathrm{O}}=75^{\circ} \mathrm{K} ; \mathrm{L}=1700 \mathrm{~kJ} / \mathrm{kg}, \mathrm{L} /\left(\mathrm{C}_{\mathrm{p}}{ }_{\mathrm{p}}\right)=15$, Maximum pyrolysis length, $\mathrm{z}_{\mathrm{p}, \max }=0.2 \mathrm{~m}$; time step $\mathrm{dt}=0.1 \mathrm{~s}$.

a) $z_{f} / Z_{p}$ and $z_{p}^{1 / 2}$ versus time; b) Heat release rate $\dot{Q}_{c h}^{\prime}(\mathrm{kW} / \mathrm{m})$ versus time 
A preliminary comparison of the UFSG model predictions is made with measurements of turbulent fire spread data on a vertical PMMA Wall [13]. Figure 6 shows calculations of turbulent upward flame spread rates, $z_{f}$ and $Z_{p}$ versus time, on a PMMA wall for two different initial ignition sources: a $38 \mathrm{~kW} / \mathrm{m}^{2}$ source over a length of $0.0001 \mathrm{~m}(\mathrm{Fig} .6 \mathrm{a})$ and a $30 \mathrm{~kW} / \mathrm{m}^{2}$ source over a length of $0.01 \mathrm{~m}$ (Fig. 6b). The insert in Fig. 6a shows a plot of experimental data of $z_{f}$ vs $z_{p}$ by Orloff et al. [.13) In the galculations of Fig. 6, the expressions $Z_{f}=0.052 \dot{Q}_{c h}^{\prime 2 / 3}$ and $\dot{q}_{t}^{\prime \prime}=32 \mathrm{~kW} / \mathrm{m}^{2}$ were assumed (literature values give qt $\sim 25$ to $32^{\mathrm{h}} \mathrm{kw} / \mathrm{m}^{2}$ ). Although the results are preliminary and a full sensitivity analysis on the expressions of Table I is planned, the following remarks can be made:

1) After an initial short transient period, the ratio, $z_{f} / z_{p}$ of the flame length to the pyrolysis length, and the fire spread rate, $1, e$. the slope $d z_{p} / d t$ versus $z_{p}$, are not affected by the size of the ignition source.

2) The ratio $z_{\mathrm{f}} / \mathrm{Z}_{\mathrm{p}}$ is approximately equal to 2.2 at a height $z_{\mathrm{p}}=0.5 \mathrm{~m}$ which exactly agrees with the experimental data (see insert of Fig. 6a) and decreases at larger heights, aga in in agreement with the experimental data.

3) Based on the results of Figure 6 a an exponential curve can be fitted through the $Z_{p}$ vs time curve as $Z_{p}=0.56 \exp (.006(t-350 \mathrm{~s}))$. This gives $\mathrm{d} z_{\mathrm{p}} / \mathrm{dt}=.006^{\mathrm{p}} \mathrm{z}_{\mathrm{p}}$. Compared with Orloff's data [13] where the spread velocity $d z_{p} / d t=.0044 z_{p} .964\left(z_{p}\right.$ in $\left.\mathrm{cm}\right)$, the calculated rate is higher. This is partily due to an assumed total heat flux qu $=32 \mathrm{~kW} / \mathrm{m}^{2}$ at the high end of measured fluxes (a value of $\dot{q}_{t}^{\prime \prime}=30 \mathrm{~kW} / \mathrm{m}^{2}$ is suggested in Table I) and some in-depth radiation absorption in. the experiments with clear PMMA. Calculations with a total heat flux of $q_{t}^{\prime \prime}=25 \mathrm{~kW} / \mathrm{m}^{2}$ give an exponential growth for $z_{p}$ of 0.0033 which is in better agreement with Orloff's and other data [15].

4) Considering the variety of factors affecting fire spread and the fact that the calculations were not optimized for the turbulent data, we find the agreement of the preliminary calculations with the data quite satisfactory.

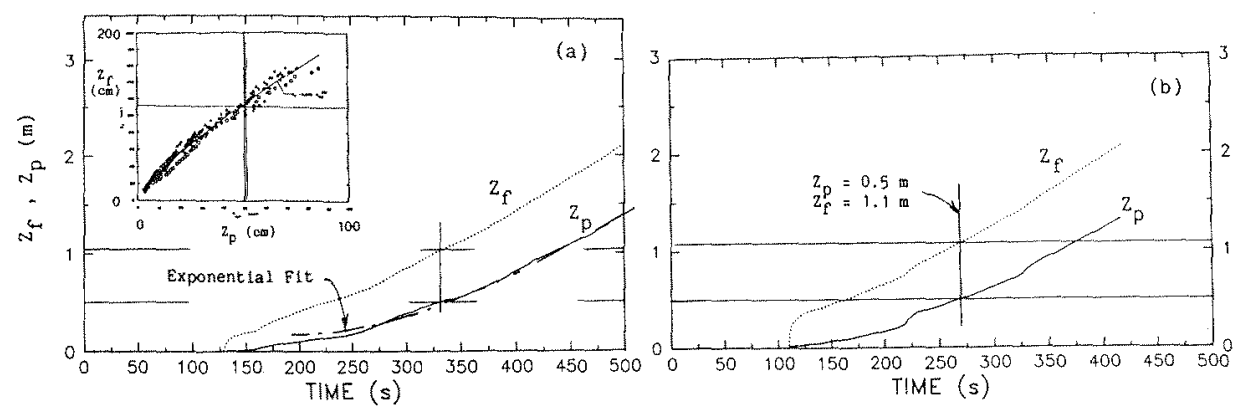

EIGURE 6 Comparison with Experimental Measurements by orloff et al. [13] Flame height, $Z_{f}$, and pyrolysis front location, $z_{p}$ versus time.

$L=1100 \mathrm{~kJ} / \mathrm{kg}, \Delta H_{c}=25300 \mathrm{~kJ} / \mathrm{kg}, C_{p}=2.2 \mathrm{~kJ} / \mathrm{kg}^{\mathrm{p}}, \mathrm{T}_{\mathrm{p}}=640^{\circ} \mathrm{K}$

Ignition source: a) $30 \mathrm{~kW} / \mathrm{m}^{2}$ over $0.0001 \mathrm{~m}$; b) $30 \mathrm{~kW} / \mathrm{m}^{2}$ over $0.01 \mathrm{~m}$ 
The major achievements of the present work are:

a) A comprehensive numerical simulation for upward flame spread and growth on noncharring materials has been compared against exact analytical solutions including transient pyrolysis, heat-up and flame spread.

b) Simple integral ordinary differential equations for transient heat-up and pyrolysis have been shown to accurately approximate (within $2 \%$ ) exact solutions or numerical solutions of detailed partial differential equations.

c) It was quantitatively demonstrated that transient pyrolysis even for noncharring materials affects significantly upward flame spread rates. These results are also supported by experimental data. [12]

d) Comparison of preliminary calculations with turbulent upward flame spread data is very satisfactory.

This work is being continued in the following areas: a) sensitivity analysis for the various parameters including the distribution of convective and radiative heat fluxes; b) extension of the numerical simulation to charring materials; c) extension to materials having significant in-depth absorption by radiation (e.g. clear PMMA); and d) comparison with on-going upward flame spread data in turbulent wall fires.

\section{REFERENCES}

1. Delichatsios, M.A., "Burning and Upward Flane Spread on Vertical Material Surfaces," FMRC Technical Report, J.I. OQ0J1.BU, 1988.

2. Delichatsios, M.M., Mathews, M.K., Delichatsios, M.A., "Upward Fire Spread Simulation Code" FMRC Report J.I. OROJ2.BU, 1990.

3. Mitler, H.E., "Predicting the Spread Rates of Eires on Vertical Surfaces," 23rd (International) Symposium on Combustion, 1990.

4. Hasemi, Y., "Thermal Modeling of Upward Flame Spread," Proceedings of the First International Symposium, Fire Safety Science, pg. 87, 1986.

5. Quintiere, J., Harkleroad, M. and Hasemi, Y., "Wall Flames and Implications for Upward Flame Spread," AIAA Paper No. 85-0456, 1985.

6. Delichatsios, M.A., Combustion Science and Technology, 34, 1984.

7a. Markstein, G.H., and de Ris, J., 23rd International Symposium on Combustion, 1990; 7b, Personal Communication, Jan. 1990.

8. Steward, F.R., Combustion and Flame, $\underline{8}, 171,1964$.

9. Delichatsios, M.A., Orloff, L., Delichatsios, M.M., "The Effects of Fuel Sooting Tendency on Flame Radiation in Luminous Turbulent Jet Flames," submitted for publication to Combustion Science and Technology, 1990.

10. Delichatsios, M.A., "Modeling of Aireraft Cabin Fires," FMRC Report, J.I. OHOJ2.BU, May 1984.

11. Ahmad, T., "Investigation of the Combustion Region of Fire - Induced Plumes Along Upright Surfaces," Ph.D. Thesis, The Pennsylvania State University, Department of Mech. Engineering, August 1978.

12. Annamalai, K. and Sibulkin, M., "Flame Spread Over Combustible Surfaces for Laminar Flow Systems, Part II: Flame Heights and Fire Spread Rates," Combustion Science and Technology, 19, 185 (1979).

13. Orloff, L., de Ris, J. and Markstein, G.H., 15th International Symposium on Combustion, pp 183-192, 1974.

14. Delichatsios, M.M. and Delichatsios, M.A., "Effects of Transient Pyrolysis on Wind Assisted and Upward Flame Spread," accepted for presentation at the ASME/JSME Heat Transfer Meeting, March 17-22, 1991.

15. Hasemi, Y. and Yoshida, M., Personal Communication, January 1991. 